\title{
White Matter Injury Following Prolonged Free Radical Formation in the 0.65 Gestation Fetal Sheep Brain
}

\author{
ANNA-KARIN WELIN, MATS SANDBERG, ANNA LINDBLOM, PERNILLA ARVIDSSON, \\ ULF A. NILSSON, INGEMAR KJELLMER, AND CARINA MALLARD \\ Perinatal Center, Department of Obstetrics and Gynecology [A.-K.W.], Department of Physiology and \\ Pharmacology [M.S., A.L., P.A., C.M.], Department of Nephrology [U.A.N.], and Department of Pediatrics \\ [I.K.], University of Göteborg, 40530 Göteborg, Sweden
}

\begin{abstract}
Free radicals seem to be involved in the development of cerebral white matter damage after asphyxia in the premature infant. The immature brain may be at increased risk of free radical mediated injury, as particularly the preterm infant has a relative deficiency in brain antioxidants systems, such as superoxide dismutase and glutathione peroxidase. In vitro studies show that immature oligodendrocytes express an intrinsic vulnerability to reactive oxygen species and free radical scavengers are able to protect immature oligodendrocytes from injury. The aim of this study was to examine the formation of ascorbyl radicals as a marker of oxidative stress in the preterm brain in association with cerebral white matter injury after intrauterine asphyxia. Fetal sheep at 0.65 gestation were chronically instrumented with vascular catheters and an occluder cuff around the umbilical cord. A microdialysis probe was placed in the periventricular white matter. Fetal asphyxia was induced by occlusion of the umbilical cord for $25 \mathrm{~min}(n=10)$. Microdialysis samples were collected for $72 \mathrm{~h}$ and analyzed for ascorbyl radicals using electron spin resonance. Five instrumented fetuses served as controls. Three days after the insult, fetal brains were examined for morphologic injury. Umbilical cord occlusion resulted in
\end{abstract}

\section{ABSTRACT}

prolonged and marked increase in ascorbyl radical production in the brain in connection with white matter injury, with activation of microglia cells in periventricular white matter and axonal injury. These data suggest that reperfusion injury following asphyxia in the immature brain is associated with marked free radical production. (Pediatr Res 58: 100-105, 2005)

$\quad$ Abbreviations
AMPA, alpha-amino-3-hydroxy-5-methyl-4-isoxazole
propionic acid
CSF, cerebral spinal fluid
DAB, 3,3-diamionbenzidine
DHA, dehydroascorbate
DMPD, dimethyl-o-phenylenediamine
ESR, electron spin resonance
JNK, c-Jun N-terminal kinase
MPA, metaphosphoric acid
NBQX, 6-nitro-7-sulfamoylbenzo(f)quinoxaline-2,3-dione
PVL, periventricular leukomalacia
SDA, semi-dehydroascorbate

White matter damage is a prominent form of brain injury in the premature infant and is associated with subsequent development of cerebral palsy and cognitive impairment $(1,2)$. The lesions of the white matter can either be focal, typically localized bilaterally to the external angles of the lateral ventricles (so-called PVL), or diffuse throughout the subcortical white matter $(3,4)$. Immaturity of the cerebral vascular architecture and poor autoregulation of cerebral blood flow are

Received August 19, 2004; accepted November 2, 2004.

Correspondence: Carina Mallard, Ph.D., Department of Physiology, University of Göteborg, 40530 Göteborg, Sweden; e-mail: carina.mallard@fysiologi.gu.se

This work was supported by the Swedish Medical Research Council, the Åhlén Foundation, the Sven Jerring Foundation, the Magnus Bergvall Foundation, the Wilhelm and Martina Lundgren Foundation, the Linnéa and Josef Carlsson Foundation, the Frimurare Barnhus Foundation, Göteborg Medical Society, and Åke Wibergs Foundation.

DOI: 10.1203/01.PDR.0000163388.04017.26 major factors related to the susceptibility of the periventricular regions to ischemia (5). The development of white matter damage in preterm infant brains and subsequent disturbance of myelination takes place in areas with abundance of oligodendrocyte progenitor cells (6).

Oxidative stress resulting in the production of free radicals seems to play a key role in the pathogenesis of white matter damage. Recent studies have shown evidence of oxidative and nitrosative injury to premyelinating oligodendrocytes in autopsy brain tissue from premature infants with PVL (7) and high levels of lipid peroxidation products are found in the CSF of preterm infants with PVL (8). Immature oligodendrocytes in vitro are particularly vulnerable to reactive oxygen species, and free radical scavengers protect immature oligodendrocytes from injury $(9,10)$. 
Evidence of free radical formation has been demonstrated in the term fetal sheep brain after asphyxia or cerebral ischemia (11-13). However, the role of free radical formation in connection to white matter injury in the 0.65 gestation fetal sheep is not known. We have previously demonstrated development of cerebral white matter injury, similar to that seen in preterm infants, after intrauterine asphyxia in the 0.65 gestational fetal sheep (14). A preliminary report indicated that a single asphyctic episode in the 0.65 gestation fetal sheep provoked a longstanding production of SDA radicals (ascorbyl radicals) in white matter of the brain (15). We have also previously shown an increase in SDA radicals in neonatal rat brain after hypoxiaischemia (16). The aim of this study was therefore to examine the formation of ascorbyl radicals in the preterm brain in connection to cerebral white matter injury after intrauterine asphyxia. Furthermore, hypoxia has been shown to affect plasma ascorbate levels in rats and rabbits (17) and we therefore also examined the effect of fetal asphyxia on plasma ascorbate in the fetal sheep.

\section{MATERIALS AND METHODS}

Surgical procedure. Fifteen pregnant ewes of mixed breed underwent aseptic surgery (isoflurane 1.5\%) at $90.6 \pm 0.4 \mathrm{~d}$ of gestation (term $=$ approximately 147 d) as previously described (Mallard 2003). Briefly, a vascular occluder was placed around the umbilical cord (InVivo Metrics Inc., Healdsburg, CA). A microdialysis probe (CMA/20, CMA Microdialysis AB, Solna, Sweden) was placed in the subcortical white matter of the left hemisphere of the brain (in 12 of the 15 studied fetuses). The probe was implanted through a burr hole, $6 \mathrm{~mm}$ in front of bregma, $4 \mathrm{~mm}$ lateral to the midline, and $13 \mathrm{~mm}$ down. Catheters were implanted in both axillary arteries of the fetus. One catheter was placed in the amnion and secured to the fetus. Finally, a catheter was inserted in the saphenous vein of the ewe.

After surgery, the ewes were kept in individual cages with free access to food and water. The animals were allowed to recover from surgery for 48 -96 $\mathrm{h}$ before studies began. Antibiotics (gentamycin, $5 \mathrm{mg} / \mathrm{kg}$ i.v.) were administered to the ewe during the postoperative period.

Experimental procedures. Fetuses were randomly allocated to asphyxia ( $n$ $=10)$ or control $(n=5)$ groups at $94.0 \pm 0.4$ and $93.2 \pm 0.4 \mathrm{~d}$ of gestation, respectively. Asphyxia was induced by inflation of the umbilical vascular occluder for $25 \mathrm{~min}$. Fetal blood samples were drawn at specific time intervals throughout the study and immediately analyzed for blood gases $\left(\mathrm{Po}_{2}, \mathrm{PCO}_{2}, \mathrm{pH}\right.$, $\mathrm{SO}_{2}$, and base excess) and glucose and lactate (ABL 725, Radiometer, Copenhagen, Denmark). In six animals subjected to asphyxia, additional blood samples $(1 \mathrm{~mL})$ were collected at $1 \mathrm{~h}$ before asphyxia and at $2 \mathrm{~h}, 6 \mathrm{~h}$, and $24 \mathrm{~h}$ after asphyxia and plasma was frozen and stored at $-80^{\circ} \mathrm{C}$. Tubing from the microdialysis probe was connected to a pump for continuous infusion with Ringer's solution ( $\mathrm{KCl} 4 \mathrm{mM}, \mathrm{CaCl}_{2} 3 \mathrm{mM}, \mathrm{NaCl} 0.15 \mathrm{M}, \mathrm{pH}$ 6, Fresenius Kabi AG, Bad Homburg, Germany) at a rate of $1 \mu \mathrm{L} / \mathrm{min}$. Microdialysate was sampled in $60 \mu \mathrm{L}$ aliquots at $+4^{\circ} \mathrm{C}$ (Univentor 820, Agnthos, Lidingö, Sweden) and stored at $-80^{\circ} \mathrm{C}$ within $10 \mathrm{~h}$. The sample time from the probe tip to the collection vial was $15 \mathrm{~min}$. The half-life of ascorbyl radicals in plasma in room temperature is $1 \mathrm{~h}$ and at $4^{\circ} \mathrm{C} 24 \mathrm{~h}$ (Nilsson U, personal communication). Samples were collected hourly before the occlusion and for $72 \mathrm{~h}$ after the occlusion. Continuous blood pressure was recorded on a Grass polygraph (Grass-Telefactor, West Warwick, RI). Three days after the experimental procedure, ewes and fetuses were killed by a maternal overdose of sodium pentobarbitone $(130 \mathrm{mg} / \mathrm{kg}$, i.v. $)$.

This study was approved by the Animal Ethical Committee of the University of Göteborg (No. 46-2000).

Ascorbyl radical measurements. The dialysate was thawed and transferred into a hematocrit tube that was plugged with sealant in one end. The intensity of the SDA radical was measured with a Bruker ECS 106 EPR spectrometer (Bruker Biospin $\mathrm{GmbH}$, Rheinstetten, Germany). Spectrometer settings were as follows: field center, $3478.5 \mathrm{G}$; modulation amplitude, $1.0 \mathrm{G}$; microwave power, $10 \mathrm{~mW}$; microwave frequency, $9.74 \mathrm{GHz}$; scan range, $5 \mathrm{G}$; scan rate, $60 \mathrm{G} / \mathrm{min}$; time constant, $0.02 \mathrm{~s}, 20$ scans. The amount of SDA radical was expressed as relative change in ESR signal intensity compared with control values before the induction of asphyxia.
Ascorbate measurement. The total amount of ascorbate and DHA, i.e. total ascorbate, was quantified by HPLC as described by Tessier et al. (18). For deproteination, $3 \mu \mathrm{L}$ metaphosphoric acid $\left(0.5 \mathrm{~g}\right.$ MPA in $\left.10 \mathrm{~mL} \mathrm{H}_{2} \mathrm{O}\right)$ was added to $30 \mu \mathrm{L}$ of the plasma followed by centrifugation for $10 \mathrm{~min}$ at 10,000 $\times g$. To oxidize ascorbate to DHA, $20 \mu \mathrm{L}$ of the supernatant was mixed with $10 \mu \mathrm{L} 0.01 \mathrm{M}$ iodine in $2.7 \%$ potassium iodide $(1 \mathrm{~min})$. The reaction was terminated and the excess of iodine was reduced by adding $20 \mu \mathrm{L}$ of $0.01 \mathrm{M}$ thiosulphate to the samples $(1 \mathrm{~min})$. Total ascorbate was derivatized by adding and mixing $50 \mu \mathrm{L}$ phosphate buffer $\left(25.4 \mathrm{~g} \mathrm{NaH}_{2} \mathrm{PO}_{4}\left(\mathrm{H}_{2} \mathrm{O}\right)\right.$ in $100 \mathrm{~mL} \mathrm{H}_{2} \mathrm{O}$ adjusted to $\mathrm{pH} 5.4$ with concentrated $\mathrm{NaOH}$ ) and $20 \mu \mathrm{L}$ DMPD (10 mg in 1 $\mathrm{mL} 1 \mathrm{M} \mathrm{HCl}$ diluted to $10 \mathrm{~mL}$ ) with the samples to form a fluorescent quinoxaline derivative. The DHA-DMPD derivative is stable for at least $2 \mathrm{~h}$ at room temperature (18). One hundred microliters from the samples was taken for the HPLC analysis of DHA-DMPD. Standard concentrations of ascorbate were prepared daily $\left(10 \mathrm{mg}\right.$ ascorbate in $\left.100 \mathrm{~mL} \mathrm{H}_{2} \mathrm{O}\right)$ and diluted to 10,25 , and $50 \mathrm{mg} / \mathrm{L}$ ascorbate. The recovery of known amount of ascorbate added to plasma was close to $100 \%$.

DHA quantification. Analysis of total ascorbate was performed using a Varian 5500 LC pump coupled to a Jasco fluorescent detector. The DMPDDHA derivative was separated on a Nucleosil $\mathrm{C}_{18}$ column $(200 \times 4.6 \mathrm{~mm}$; Macherey-Nagel, Duren, Germany). The mobile phase was 50\% methanol and $50 \%$ phosphate buffer $(50 \mathrm{mM}, \mathrm{pH} 5.28)$ and the column was eluted at 1.0 $\mathrm{mL} / \mathrm{min}$. The derivative was detected using excitation at $360 \mathrm{~nm}$ and emission at $440 \mathrm{~nm}$. Total ascorbate in plasma and dialysates was quantified using standards of known concentration. Standards at three different concentrations were always analyzed together with a set of samples.

Histology. Fetal brains were perfused in situ through the carotid arteries using saline $(0.9 \% \mathrm{NaCl})$ followed by $5 \%$ formaldehyde in phosphate buffer (Histofix), removed, and weighed. Brains were postfixed in 5\% formaldehyde overnight, dehydrated in alcohol solutions, and embedded in paraffin. Coronal sections $(8 \mu \mathrm{m})$ of the forebrain, including the cerebral cortex, underlying white matter, striatum, hippocampus, and thalamus were cut on a microtome. Sections were stained with acid fuchsin and thionin (Mallard 1993) for morphologic analysis and adjacent sections were used for immunohistochemical analysis as described below.

Immunoreactivity for axonal neurofilaments was visualized using a monoclonal antiphosphorylated-neurofilament antibody (SMI312, Sternberger Monoclonals, Lutherville, MD). Sections were boiled in citric acid buffer $(0.01$ $\mathrm{M}, \mathrm{pH}$ 6.0), blocked for endogenous peroxidase ( $0.6 \%$ in methanol for $10 \mathrm{~min}$ ), and blocked with $10 \%$ horse serum $(30 \mathrm{~min})$. The sections were then incubated with the primary antibody (1:2000 in PBS) for $1 \mathrm{~h}$ followed by the secondary antibody (horse-anti-mouse biotinylated 1:250, Vector Laboratories, Burlingame, CA) for $30 \mathrm{~min}$. The sections were visualized using the avidin-biotin peroxidase complex (Vector Laboratories) and DAB. Microglia were visualized using lectin histochemistry. Sections were boiled in citrate buffer $(0.01 \mathrm{M}$, $\mathrm{pH}$ 6.0), incubated with $15 \mu \mathrm{L} / \mathrm{mL}$ Griffonia simplicifolia isolectin- $\mathrm{B}_{4}$ horseradish peroxidase labeled, L5391 (Sigma Chemical Co., St. Louis, MO) overnight $\left(4^{\circ} \mathrm{C}\right)$ and visualized using DAB as described above.

Analysis of brain injury. Evenly spaced sections throughout the brain, stained with acid fuchsin/thionin, were examined for gross morphologic changes using light microscopy. To count activated microglia cells, brain sections stained for isolectin- $\mathrm{B}_{4}$ were examined at $40 \times$ magnification and the microscope images were displayed on a computer monitor. The number of activated microglia cells was determined by counting the number of positive cells in the periventricular white matter in two fields of view $\left(0.0735 \mathrm{~mm}^{2}\right)$ at two brain levels (striatum and anterior hippocampus). Adjacent sections, stained for phosphorylated neurofilament (NF) were scored according to the following criteria: normal $=0$, patchy loss of staining $=1$, and marked loss of staining $=2$. The presence ( score $=1$ ) or absence (score $=0$ ) of neuronal injury was also analyzed in acid fuchsin/thionin stained sections at the level of striatum, hippocampus, and thalamus. Cortical gray matter was also noted in these sections. A total brain injury score was calculated as the sum of the NF, striatum, hippocampus, and thalamus scores (maximum score $=5$ ). All analysis was performed by an observer unaware of the treatment group of the animals. In some cases, there was evidence of the probe in the tissue (Fig. 1) and, therefore, to avoid any influence of the microdialysis probe on brain morphology, only the right hemisphere was examined.

Statistics. Animals subjected to asphyxia were compared with control animals with respect to blood gas measurements and ascorbyl radical and ascorbate measurements in microdialysis samples by repeated measures ANOVA followed by Fischer's PLSD posthoc analysis. Pre- and post asphyctic ascorbate and ascorbyl radical measurements in plasma samples were compared by ANOVA followed by Fischer's PLSD posthoc analysis. Microglia cell counts were compared using unpaired $t$ test. Regression analysis was performed between ascorbyl radical measurements in microdialysis samples and microglia cell counts or brain injury score. Statistical significance was set 


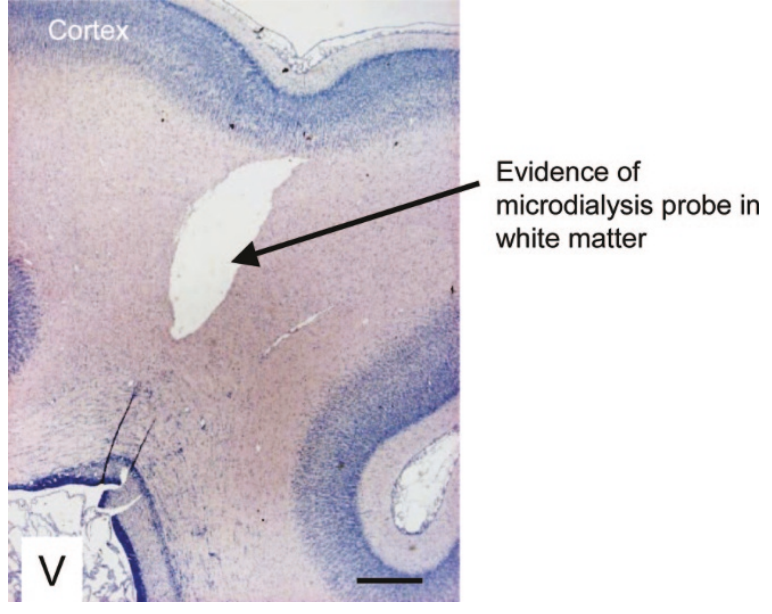

Figure 1. Coronal section of the periventricular white matter at the level of the anterior striatum. There is evidence of the placement of the microdialysis probe in the white matter. No corresponding disturbance in cerebral architecture was observed in the contralateral hemisphere. Section stained with acid fuchsin and thionin. $V$, lateral ventricle. Scale bar $=0.32 \mathrm{~mm}$.

to $p<0.05$. Statistical analyses were performed using the StatView for Windows (5.0.1, SAS, Cary, NC). All data are presented as mean \pm SD.

\section{RESULTS}

There were no differences in initial blood gas measurements between animals in the control group and those that were subjected to umbilical cord occlusion. During the umbilical cord occlusion, severe transient asphyxia developed as shown in Table 1.

Microdialysis sampling was successful in seven fetuses subjected to umbilical cord occlusion and in five control animals. Intrauterine asphyxia resulted in a prolonged and marked increase in ascorbyl radical production in the brain, from 4 to $16 \mathrm{~h}$ of reperfusion (Fig. 2). There were no changes in the production of ascorbyl radical formation in control animals over time. No changes occurred in ascorbyl radical formation in the plasma after asphyxia compared with preasphyctic values (Fig. 3A). Total ascorbate levels did not change in either brain or plasma samples after umbilical cord occlusion (Fig. 3, $B$ and $C$ ).
All fetuses subjected to umbilical cord occlusion demonstrated activation of microglia cells in periventricular white matter, the internal and external capsule. The microglia activation was widespread throughout these brain regions. There were very few activated microglia cells in control animals (19 \pm 18 cells $/ \mathrm{mm}^{2}$ ) compared with asphyxiated fetuses (226 \pm 130 cells $/ \mathrm{mm}^{2}, p=0.0112$ ). Axonal injury was evident as loss of phosphorylated neurofilament immunoreactivity in animals subjected to umbilical cord occlusion (Fig. 4, Table 2). Eight out of nine fetuses also demonstrated some degree of gray matter injury in hippocampus, striatum, or thalamus (Table 2). Neuronal damage was never seen in cerebral cortex (data not shown). Three days after umbilical cord occlusion, no cystic lesions (PVL-like) were observed in the brain. Three animals subjected to asphyxia and one of the control fetuses demonstrated enlarged ventricles.(Fig. 5)

\section{DISCUSSION}

A marked and prolonged increase in ascorbyl radical formation in association with white matter injury was demonstrated after an acute episode of fetal asphyxia. Analogous to our previous study, umbilical cord occlusion in the 0.65 gestation fetal sheep resulted in cerebral white matter damage (14), which is similar to that seen in some premature infants who later develop neuropathological disorders (5). The white matter damage was characterized by a reduction in axonal neurofilament staining and microglia activation, with a distribution throughout the subcortical regions. Similarly, in preterm infants, a diffuse component of PVL is often seen, which is characterized by gliosis in subcortical white matter regions (4).

Using ESR, a significant long-lasting increase in ascorbyl radical formation was detected in the cerebral white matter after asphyxia. Ascorbate, or vitamin $\mathrm{C}$, is a key antioxidant in biology, and its reaction, e.g. with oxygen radicals, gives rise to SDA. This relatively stable free radical is generally accepted as a marker of oxidative stress (19). The formation of reactive oxygen species after asphyxia may be due to multiple mechanisms. The present study may be viewed as a model of reperfusion as prolonged umbilical cord occlusion in the 0.65 gestation fetal sheep results in transient systemic hypotension,

Table 1. Arterial blood gases, lactate, and glucose measurements (control, $\mathrm{n}=4$; asphyxia, $\mathrm{n}=10$ )

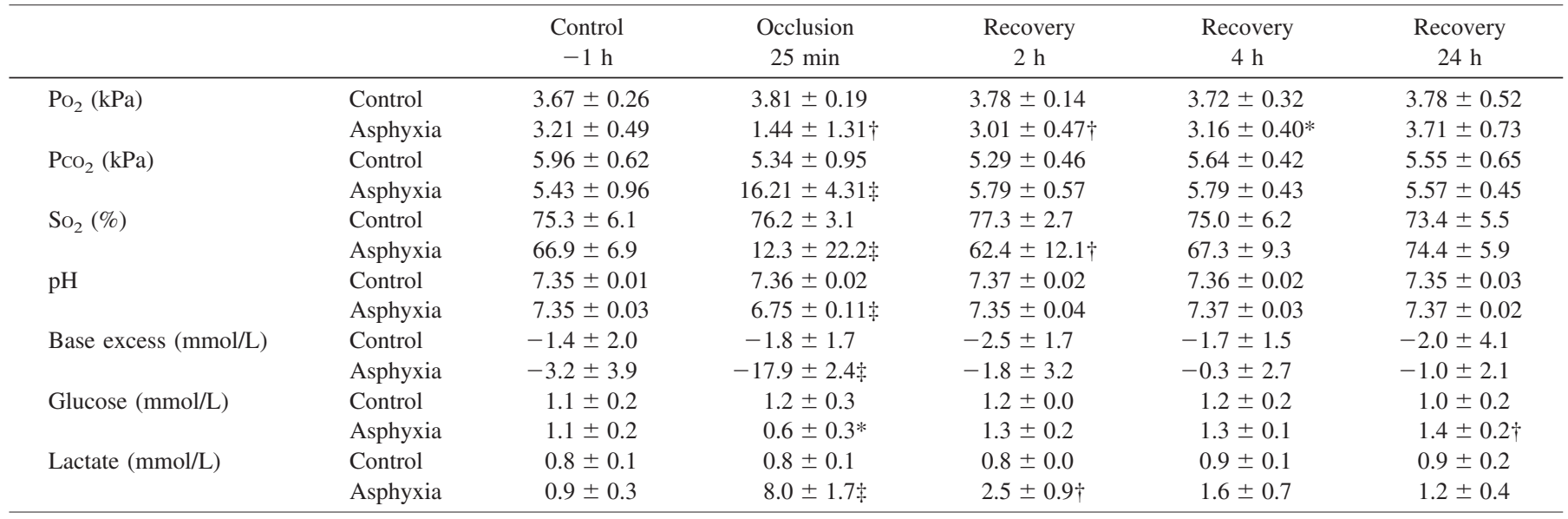

$* p<0.05 ; \dagger p<0.01 ; \ddagger p<0.001$ compared with controls. 
Ascorbyl radicals in brain

(\% of pre-insult)

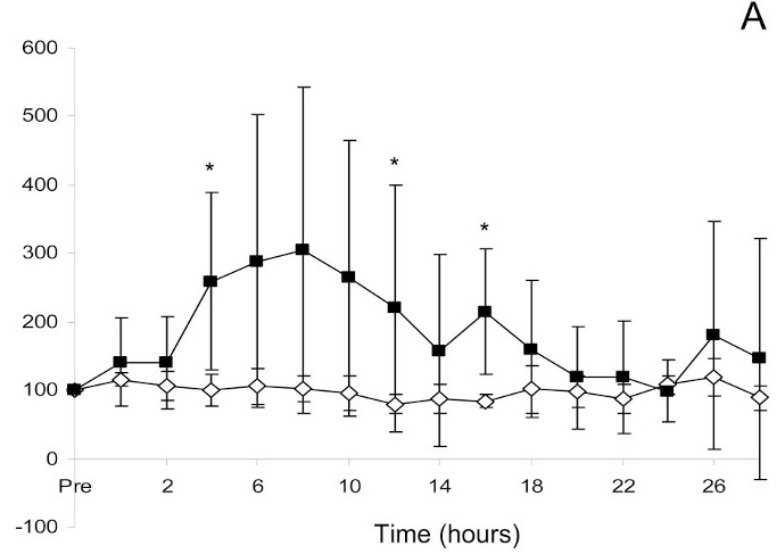

Ascorbyl radicals in brain

(\% of pre-insult)

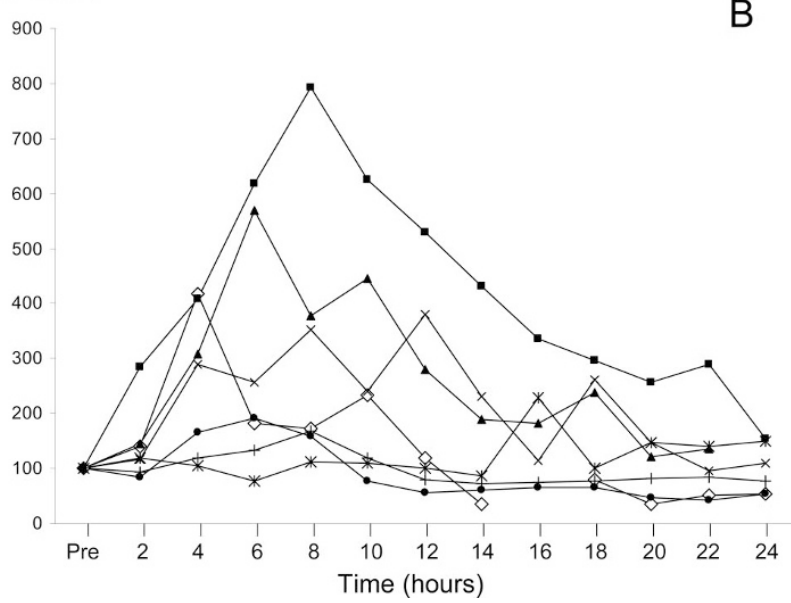

Figure 2. Ascorbyl radicals were measured in microdialysate from periventricular brain tissue after umbilical cord occlusion or in sham-operated fetuses and are shown as relative changes compared with preasphyctic values. $(A)$ Fetuses subjected to asphyxia $(n=7)$ are shown in black boxes and control fetuses $(n=5)$ are shown in white boxes. Fetuses responded with an increase in ascorbyl radical production that started $4 \mathrm{~h}$ after the beginning of the occlusion and lasted for $16 \mathrm{~h}$. The data are presented as mean $\pm \mathrm{SD}$. $(B)$ Ascorbyl radical measurements from the seven individual fetuses subjected to umbilical cord occlusion. At least four out of seven fetuses demonstrated marked increase in ascorbyl radical formation. which is associated with cerebral hypoperfusion followed by restoration of cerebral blood flow $(20,21)$. During the reperfusion phase, the superoxide radical may be generated via oxidation of hypoxanthine, which, in the presence of ferrous iron, may result in the formation of the highly reactive and injurious hydroxyl radical. Another mechanism of free radical formation is leakage of superoxide radicals from impaired electron transport in mitochondria $(5,22)$. Reactive oxygen species are also known to be produced by activated inflammatory cells, such as neutrophils $(23,24)$ and microglia $(25)$. Activated microglia also release pro-inflammatory cytokines, including IL-1 $\beta$, IL18 , and TNF- $\alpha(26,27)$. In brain autopsies from infants with periventricular leukomalacia there was an increased expression of TNF- $\alpha$, IL- $1 \beta$, and IL- 6 compared with those without periventricular leukomalacia and these cytokines were mainly expressed by microglia cells and hypertrophic astrocytes (28). In vitro studies have shown that IL- $1 \beta$ increase oxidative activity of microglia (29). This is consistent with our results, which show a strong activation of microglia in the damaged white matter.

Several studies have examined the formation of free radicals in the term fetal brain after cerebral ischemia, using online microdialysis techniques. In these studies, either the measurements were made in the cerebral gray matter (11) or the production of radicals was not studied in connection with brain injury analysis $(12,30)$. However, an increase in free radical production has been demonstrated in the CSF in premature infants with white matter injury (8). Buonocore et al. (31) have shown increased free radical generation and oxidation protein products in umbilical vein blood samples in hypoxic preterm newborns compared with normoxic newborns. Furthermore, neuropathological evidence of both oxidative stress and lipid peroxidation has been found in premyelinating oligodendrocytes in autopsy brains from premature children with PVL (7). In the late gestation fetal sheep, increased levels of hydrogen peroxide and thiobarbiturate-reactive substances (TBARS), as markers of oxidative stress, were found at particularly high levels in the white matter compared with the gray matter at $72 \mathrm{~h}$ after asphyxia (13). Free radical scavengers appear to be principally protective against the white matter injury after hypoxia in brain slices (32), suggesting that the white matter may be particularly vulnerable to free radical formation.

The mechanisms of free radical-induced white matter damage remain unclear. However, free radicals are known to be toxic to oligodendrocytes, particularly progenitor cells $(9,33)$,

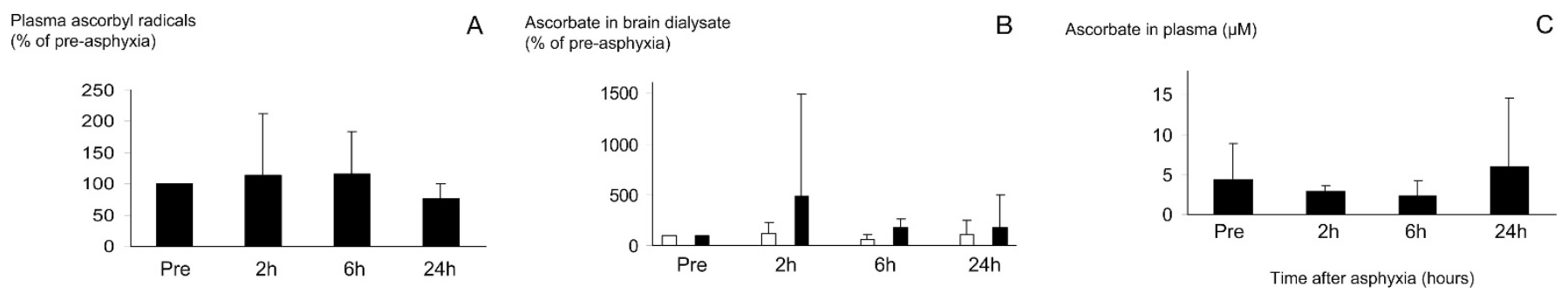

Figure 3. (A) Ascorbyl radicals in plasma in fetuses subjected to asphyxia $(n=6)$ are shown as relative changes compared with preasphyctic values. No significant changes were observed $(p>0.05)$. (B) Relative changes in brain total ascorbate dialysate compared with preasphyctic values. Fetuses subjected to asphyxia $(n=7)$ are shown in black bars and control animals $(n=5)$ are shown in white bars. No significant changes were observed $(p>0.05)$. $(C)$ Total amount of ascorbate in plasma in asphyctic fetuses $(n=6)$ is shown. No significant changes were observed $(p>0.05)$. 


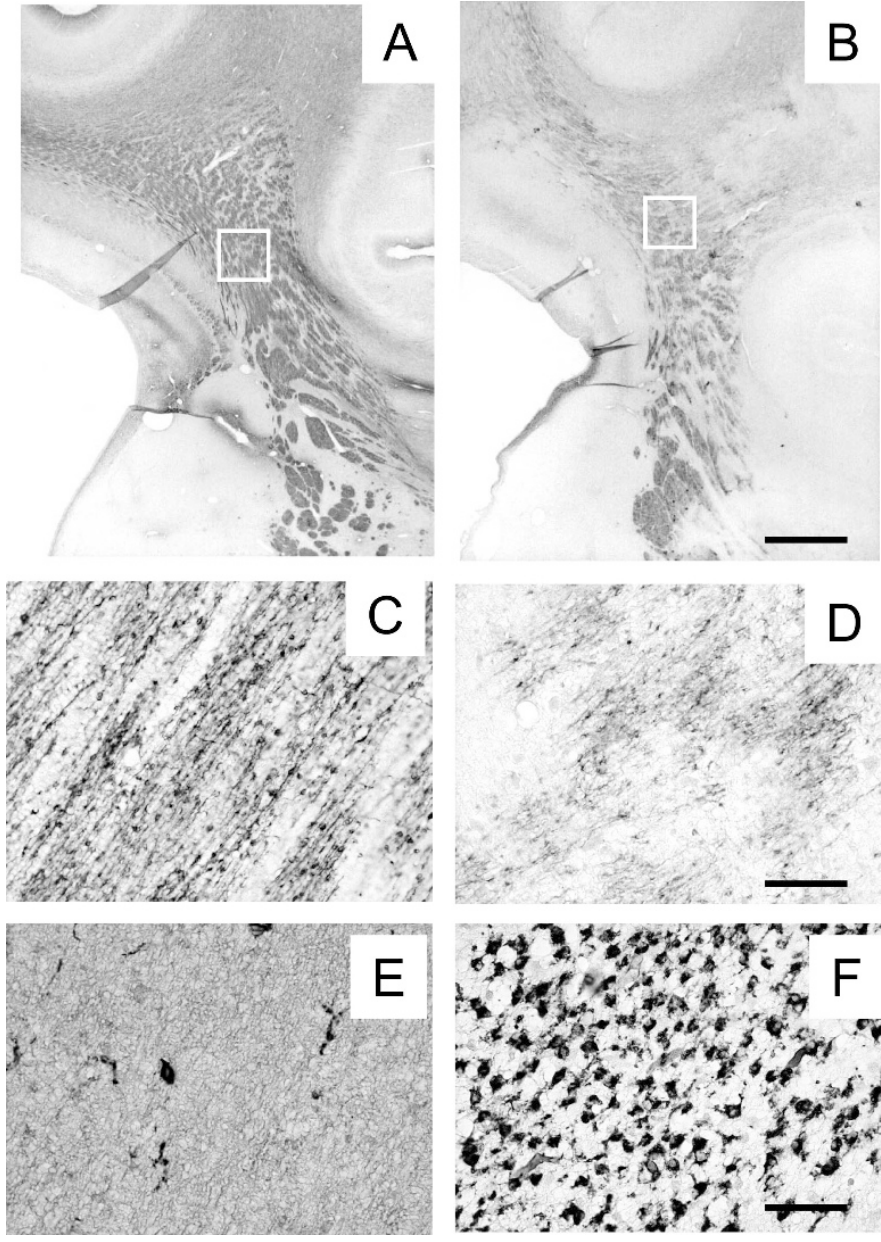

Figure 4. Photomicrographs of axonal (SMI 312) and microglia (lectin) staining, $3 \mathrm{~d}$ after the insult are shown in control animals $(A, C$, and $E)$ and in animals after asphyxia $(B, D$, and $F)$ in the periventricular white matter. Higher magnification of the white boxes in $A$ and $B$ are shown in $C-F$. There was a loss of axonal staining in asphyxiated animals. In these areas there was a significant microglia activation $(F)$. Scale bar in $A$ and $B=0.45 \mathrm{~mm}$, in $C-F=60 \mu \mathrm{m}$.

and the increased susceptibility to oxidative stress has been correlated to low glutathione and high iron content in oligodendroglial precursors (34). In support of this, free radical scavengers protect immature oligodendrocytes from injury (10). Furthermore, white matter injury after hypoxia-ischemia in neonatal rats is attenuated by 6-nitro-7-sulfamoylbenzo(f)quinoxaline-2,3-dione (NBQX) treatment, suggesting an AMPA-receptor mediated process (35). Interestingly, in vitro studies show that the AMPA-induced death of progenitor oligodendrocytes involves free radicals, activation of the JNK and caspase 3 (36).

A contributing factor to the extensive ascorbyl radical formation in the immature brain may be the relative deficiency of free radical scavengers in the preterm fetus and/or infant. Animal studies have shown lower activities of antioxidants in fetal lung and other tissues $(37,38)$ and clinical studies have shown decreased activity of $\mathrm{Cu} / \mathrm{Zn}$ superoxide dismutase in erythrocytes sampled from the umbilical cord from preterm compared with term infants (39). Antioxidant enzymes are also low in the immature murine brain (40) and glutathione levels in the brain decrease further following hypoxia-ischemia in neonatal rats (41). Ascorbate is a recognized antioxidant in the brain, which reacts with several different superoxide, hydroxyl, and peroxyl radicals, resulting in the formation of ascorbyl radicals (42). Katz et al. (43) measured a $48 \%$ reduction of ascorbate levels followed by reduction of other antioxidants (glutathione and thiol groups) in the hippocampus 10 min after reperfusion. A reduction in tissue ascorbate levels was also observed in the rat brain after cerebral ischemia (44). In contrast, there were no changes in the brain but an transient early increase in plasma ascorbate after acute hypoxia in rats and rabbits (17). In the present study, we did not find any significant changes in either brain dialysate or plasma ascorbate, which could be due to the lack of samples within the first $2 \mathrm{~h}$ of reperfusion.

\section{CONCLUSION}

In conclusion, we have shown a long-lasting and marked increase in free radical production in the cerebral white matter after intrauterine asphyxia in the 0.65 gestation fetal sheep in association with cerebral white matter damage. The prevention/reduction of free radical production in immature white

Table 2. Brain injury in control fetuses and after fetal asphyxia

\begin{tabular}{|c|c|c|c|c|c|c|}
\hline Sheep no. & Group & $\begin{array}{c}\mathrm{NF} \\
\text { white matter }\end{array}$ & Striatum & Hippocampus & Thalamus & $\begin{array}{c}\text { Brain } \\
\text { injury score }\end{array}$ \\
\hline 0102 & Control & 0 & 0 & 0 & 0 & 0 \\
\hline 0202 & Control & 0 & 0 & 0 & 0 & 0 \\
\hline 0701 & Control & 0 & 0 & 0 & 0 & 0 \\
\hline 2302 & Control & 0 & 0 & 0 & 0 & 0 \\
\hline 0600 & Asphyxia & 2 & 1 & 1 & 1 & 5 \\
\hline 0902 & Asphyxia & 2 & 1 & 1 & 1 & 5 \\
\hline 1000 & Asphyxia & 1 & 1 & 1 & 1 & 4 \\
\hline 1002 & Asphyxia & 0 & 0 & 0 & 1 & 1 \\
\hline 1100 & Asphyxia & 2 & 1 & 1 & 1 & 5 \\
\hline 1301 & Asphyxia & 1 & 0 & 0 & 0 & 1 \\
\hline 1400 & Asphyxia & 2 & 1 & 1 & 1 & 5 \\
\hline
\end{tabular}

Brain sections were assessed according to the description in the Methods section. Brain injury score is the sum of the score in white matter, striatum, hippocampus, and thalamus. NF, neurofilament. 
Ascorbyl radicals

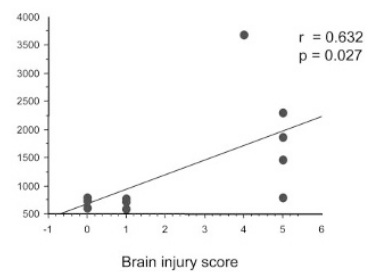

Ascorbyl radicals

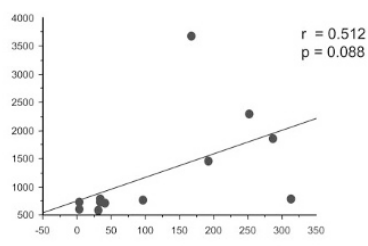

Number of microglia (per $\mathrm{mm}^{2}$ )
Figure 5. Regression analysis of the total ascorbyl radical levels from 2-14 $\mathrm{h}$ after umbilical cord occlusion and the brain injury score $(A)$ or number of microglia cells $(B)$. There was a significant correlation between the brain injury score and the degree of ascorbyl radical formation ( $p=0.027, r=0.632)$.

matter may in the future yield possibilities for potential therapeutic treatment of PVL-like injuries.

\section{REFERENCES}

1. Perlman JM 1998 White matter injury in the preterm infant: an important determination of abnormal neurodevelopment outcome. Early Hum Dev 53:99-120

2. Larroque B, Marret S, Ancel PY, Arnaud C, Marpeau L, Supernant K, Pierrat V, Roze JC, Matis J, Cambonie G, Burguet A, Andre M, Kaminski M, Breart G; EPIPAGE Study Group 2003 White matter damage and intraventricular hemorrhage in very preterm infants: the EPIPAGE study. J Pediatr 143:477-483

3. Banker BQ, Larroche JC 1962 Periventricular leukomalacia of infancy. A form of neonatal anoxic encephalopathy. Arch Neurol 7:386-410

4. Inder TE, Anderson NJ, Spencer C, Wells S, Volpe JJ 2003 White matter injury in the premature infant: a comparison between serial cranial sonographic and MR findings at term. AJNR Am J Neuroradiol 24:805-809

5. Volpe JJ 2001 Neurobiology of periventricular leukomalacia in the premature infant Pediatr Res 50:553-562

6. Back SA, Luo NL, Borenstein NS, Levine JM, Volpe JJ, Kinney HC 2001 Late oligodendrocyte progenitors coincide with the developmental window of vulnerability for human perinatal white matter injury. J Neurosci 21:1302-1312

7. Haynes RL, Folkerth RD, Keefe RJ, Sung I, Swzeda LI, Rosenberg PA, Volpe JJ, Kinney HC 2003 Nitrosative and oxidative injury to premyelinating oligodendrocytes in periventricular leukomalacia. J Neuropathol Exp Neurol 62:441-450

8. Inder T, Mocatta T, Darlow B, Spencer C, Volpe JJ, Winterbourn C 2002 Elevated free radical products in the cerebrospinal fluid of VLBW infants with cerebral white matter injury. Pediatr Res 52:213-218

9. Back SA, Gan X, Li Y, Rosenberg PA, Volpe JJ 1998 Maturation-dependent vulnerability of oligodendrocytes to oxidative stress-induced death caused by glutathione depletion. J Neurosci 18:6241-6253

10. Yonezawa M, Back SA, Gan X, Rosenberg PA, Volpe JJ 1996 Cystine deprivation induces oligodendroglial death: rescue by free radical scavengers and by a diffusible glial factor. J Neurochem 67:566-573

11. Tan WK, Williams CE, During MJ, Mallard CE, Gunning MI, Gunn AJ, Gluckman PD 1996 Accumulation of cytotoxins during the development of seizures and edema after hypoxic-ischemic injury in late gestation fetal sheep. Pediatr Res 39:791-797

12. Bagenholm R, Nilsson UA, Gotborg CW, Kjellmer I 1998 Free radicals are formed in the brain of fetal sheep during reperfusion after cerebral ischemia. Pediatr Res 43:271-275

13. Ikeda T, Murata Y, Quilligan EJ, Parer JT, Doi S, Park SD 1998 Brain lipid peroxidation and antioxidant levels in fetal lambs 72 hours after asphyxia by partial umbilical cord occlusion. Am J Obstet Gynecol 178:474-478

14. Mallard C, Welin AK, Peebles D, Hagberg H, Kjellmer I 2003 White matter injury following systemic endotoxemia and asphyxia in the fetal sheep. Neurochem Res 28:215-223

15. Kjellmer I, Lindblom A, Nilsson UA, Mallard C 2001 Long-term augmentation of free radical production in white matter of midgestation fetal sheep after a single global asphyctic episode. Perinatology 405-408

16. Bagenholm R, Nilsson UA, Kjellmer I 1997 Formation of free radicals in hypoxic ischemic brain damage in the neonatal rat, assessed by an endogenous spin trap and lipid peroxidation. Brain Res 773:132-138

17. Arad I, Sidi A, Shohami E 1985 Effect of acute hypoxia on ascorbate content of plasma, cerebral cortex, and adrenal gland. J Neurochem 45:766-769
18. Tessier F, Birlouez-Aragon I, Tjani C, Guilland JC 1996 Validation of a micromethod for determining oxidized and reduced vitamin $\mathrm{C}$ in plasma by HPLC-fluorescence. Int J Vitam Nutr Res 66:166-170

19. Buettner GR, Jurkiewicz BA 1993 Ascorbate free radical as a marker of oxidative stress: an EPR study. Free Radic Biol Med 14:49-55

20. Bennet L, Rossenrode S, Gunning MI, Gluckman PD, Gunn AJ 1999 The cardiovascular and cerebrovascular responses of the immature fetal sheep to acute umbilical cord occlusion. J Physiol 517:247-257

21. Welin AK, Blad S, Hagberg H, Rosén KG, Kjellmer I, Mallard C 2005 ECG waveform changes following intrauterine asphyxia and endotoxemia in the midgestation fetal sheep. Acta Obstet Gynecol Scand (in press)

22. Palmer L, Blair E, Petterson B, Burton P 1995 Antenatal antecedents of moderate and severe cerebral palsy. Paediatr Perinat Epidemiol 9:171-184

23. Babior BM 2000 Phagocytes and oxidative stress. Am J Med 109:33-44

24. Matsuo Y, Kihara T, Ikeda M, Ninomiya M, Onodera H, Kogure K 1995 Role of neutrophils in radical production during ischemia and reperfusion of the rat brain: effect of neutrophil depletion on extracellular ascorbyl radical formation. J Cereb Blood Flow Metab 15:941-947

25. Colton C, Wilt S, Gilbert D, Chernyshev O, Snell J, Dubois-Dalcq M 1996 Species differences in the generation of reactive oxygen species by microglia. Mol Chem Neuropathol 28:15-20

26. Chao CC, Hu S, Peterson PK 1995 Glia, cytokines, and neurotoxicity. Crit Rev Neurobiol 9:189-205

27. Hedtjarn M, Leverin AL, Eriksson K, Blomgren K, Mallard C, Hagberg H 2002 Interleukin-18 involvement in hypoxic-ischemic brain injury. J Neurosci 22:59105919

28. Yoon BH, Romero R, Kim CJ, Koo JN, Choe G, Syn HC, Chi JG 1997 High expression of tumor necrosis factor-alpha and interleukin- 6 in periventricular leukomalacia. Am J Obstet Gynecol 177:406-411

29. Smith ME, van der Maesen K, Somera FP 1998 Macrophage and microglial responses to cytokines in vitro: phagocytic activity, proteolytic enzyme release, and free radical production. J Neurosci Res 54:68-78

30. Kjellmer I, Andine P, Hagberg H, Thiringer K 1989 Extracellular increase of hypoxanthine and xanthine in the cortex and basal ganglia of fetal lambs during hypoxia-ischemia. Brain Res 478:241-247

31. Buonocore G, Perrone S, Longini M, Terzuoli L, Bracci R 2000 Total hydroperoxide and advanced oxidation protein products in preterm hypoxic babies. Pediatr Res 47:221-224

32. Omata N, Murata T, Maruoka N, Fujibayashi Y, Yonekura Y, Wada Y 2003 Different mechanisms of hypoxic injury on white matter and gray matter as revealed by dynamic changes in glucose metabolism in rats. Neurosci Lett 353:148-152

33. Husain J, Juurlink BH 1995 Oligodendroglial precursor cell susceptibility to hypoxia is related to poor ability to cope with reactive oxygen species. Brain Res 698:86-94

34. Thorburne SK, Juurlink BH 1996 Low glutathione and high iron govern the susceptibility of oligodendroglial precursors to oxidative stress. J Neurochem 67:1014-1022

35. Follett PL, Rosenberg PA, Volpe JJ, Jensen FE 2000 NBQX attenuates excitotoxic injury in developing white matter. J Neurosci 20:9235-9241

36. Liu HN, Giasson BI, Mushynski WE, Almazan G 2002 AMPA receptor-mediated toxicity in oligodendrocyte progenitors involves free radical generation and activation of JNK, calpain and caspase 3. J Neurochem 82:398-409

37. Frank L, Groseclose EE 1984 Preparation for birth into an $\mathrm{O}_{2}$-rich environment: the antioxidant enzymes in the developing rabbit lung. Pediatr Res 18:240-244

38. Hayashibe H, Asayama K, Dobashi K, Kato K 1990 Prenatal development of antioxidant enzymes in rat lung, kidney, and heart: marked increase in immunoreactive superoxide dismutases, glutathione peroxidase, and catalase in the kidney. Pediatr Res 27:472-475

39. Phylactos AC, Leaf AA, Costeloe K, Crawford MA 1995 Erythrocyte cupric/zinc superoxide dismutase exhibits reduced activity in preterm and low-birthweight infants at birth. Acta Paediatr 84:1421-1425

40. Khan JY, Black SM 2003 Developmental changes in murine brain antioxidant enzymes. Pediatr Res 54:77-82

41. Wallin C, Puka-Sundvall M, Hagberg H, Weber SG, Sandberg M 2000 Alterations in glutathione and amino acid concentrations after hypoxia-ischemia in the immature rat brain. Brain Res Dev Brain Res 125:51-60

42. Halliwell B 1996 Vitamin C: antioxidant or pro-oxidant in vivo? Free Radic Res 25:439-454

43. Katz LM, Callaway CW, Kagan VE, Kochanek PM 1998 Electron spin resonance measure of brain antioxidant activity during ischemia/reperfusion. Neuroreport 9:1587-1593

44. Flamm ES, Demopoulos HB, Seligman ML, Poser RG, Ransohoff J 1978 Free radicals in cerebral ischemia. Stroke 9:445-447 